Review

\title{
Calcaneal Quantitative Ultrasound as a Determinant of Bone Health Status: What Properties of Bone Does It Reflect?
}

\author{
Kok-Yong Chin and Soelaiman Ima-Nirwana ${ }^{\bowtie}$ \\ Department of Pharmacology, Faculty of Medicine, Universiti Kebangsaan Malaysia.
}

$\triangle$ Corresponding author: Professor Dr. Soelaiman Ima-Nirwana, M.B.B.S., PhD. Department of Pharmacology, Faculty of Medicine, Universiti Kebangsaan Malaysia, Jalan Raja Muda Abdul Aziz, 50300 Kuala Lumpur, Malaysia. Tel: 03-40405514 Fax: 03-26938205 Email: imasoel@ppukm.ukm.edu.my.

(c) Ivyspring International Publisher. This is an open-access article distributed under the terms of the Creative Commons License (http://creativecommons.org/ licenses/by-nc-nd/3.0/). Reproduction is permitted for personal, noncommercial use, provided that the article is in whole, unmodified, and properly cited.

Received: 2013.05.26; Accepted: 2013.08.14; Published: 2013.10.25

\begin{abstract}
Quantitative ultrasound (QUS) has emerged as a convenient and popular screening tool for osteoporosis. This review aimed to provide basic information on the principle of QUS measurement and discuss the properties of bone reflected by QUS indices. QUS employed high frequency sound waves generated by the device to determine bone health status in humans. In vitro studies showed that QUS indices were significantly associated with bone mineral density (BMD), bone microarchitecture and mechanical parameters. In humans, QUS indices were found to be associated with BMD as well. In addition, QUS could discriminate subjects with and without fracture history and predict risk for future fracture. In conclusion, QUS is able to reflect bone quality and should be used in the screening of osteoporosis, especially in developing countries where dual-X-ray absorptiometry devices are less accessible to the general population.
\end{abstract}

Key words: Bone; Bone mineral Density; Calcaneus; Quantitative ultrasound.

\section{Introduction}

Osteoporosis is a systematic bone disease characterized by low bone mass and deterioration of microarchitecture of the bone, leading to bone fragility and eventually fractures (1). The gold standard method recommended by the World Health Organization in the diagnosis of osteoporosis is dual-X-ray absorptiometry (DXA). Using this method, osteoporosis is defined by a bone mineral density (BMD) lower than -2.5 standard deviations (SD) of the reference BMD of Caucasian women aged 20-29 years (2). Undeniably, this simplified definition of osteoporosis eases the physicians in diagnosing and initiating treatment for osteoporotic patients. However, there are several limitations of DXA which prevent it from being used in the mass screening of osteoporosis, which is currently a rising healthcare medical condition in the developing countries (3). Quantitative ul- trasound (QUS) is a bone health assessment technique which has gained much popularity in recent years since its introduction in 1984. Compared to DXA, QUS offers wider accessibility to the public because it is portable, easier to handle, lower in cost and does not emit ionizing radiation (4). This technology has been used to determine the bone health status in women (5), men (6), children (7) and in certain cases, infants (8).

The ultrasound is a type of sound wave with a frequency exceeding the normal auditory range of humans $(>20 \mathrm{kHz})$. The frequency used in QUS usually lies between $200 \mathrm{kHz}$ and $1.5 \mathrm{MHz}$. The sound waves produced by unique piezoelectric probes are emitted and travelled longitudinally or horizontally through the bone under study. There are usually two probes on the QUS device: the emission and receiver 
probes. The segment of bone under study will be placed between these probes and the ultrasound waves emitted from the emission probes through the bone will be sensed by the receiver probe (9).

There are two types of QUS depending on the axis the ultrasound waves take to travel through the bone. Horizontal transmission uses probes that measure the speed of sound on the cortical layer of the bone at a fixed distance. The segments of bone measured as such are the forearm, tibia and radius. Longitudinal transmission is more often used and the bone segment measured is the calcaneus (4). According to the International Society of Clinical Densitometry (ISCD), calcaneal QUS is the only recognized measurement of QUS as the determinant of bone health status because more research has been performed on the calcaneus as compared to the other bone segments (10). Besides, the calcaneus consists of $95 \%$ trabecular bone and possesses two lateral surfaces (11), which facilitates the movement of ultrasound through it. Therefore, this discussion will emphasize on this measurement technique, which is the calcaneal QUS.

\section{QUS parameters and the bone properties they reflect}

Two parameters commonly generated by QUS are the speed of sound (SOS) and the broadband ultrasound attenuation (BUA). The speed of sound refers to the division of transmission time of the sound waves by the length of the body part studied. The unit used in the measurement of SOS is meter per second $(\mathrm{m} / \mathrm{s})$. Broadband attenuation of sound refers to the slope between attenuation of sound signals and its frequency, and the unit used is $\mathrm{dB} / \mathrm{MHz}$. Attenuation occurs because the energy is absorbed by the soft tissue and bone when the sound waves travel through them. Currently, more sophisticated QUS indices derived from these two basic measurements are available, such as amplitude-depend SOS (AD-SOS), stiffness index (SI), quantitative ultrasound index (QUI) and estimated BMD (eBMD). Some researchers suggested that these composite parameters are more useful in the determination of subjects with low bone health status (9).

Previous in vitro studies examining the relationship between calcaneal QUS and bone properties found that SOS was closely related to BMD (12-16). Toyras et al. indicated that this relationship was strong, with a coefficient of correlation (r) of 0.888 (17). Significant correlations between SOS with microarchitecture indices of the bone, such as bone volume (BV/TV), bone surface (BS/TV), number of nodes (N.Nd.), trabecular number (Tb.N.), trabecular thickness (Tb.Th.) and trabecular separation (Tb.Sp.) were also discovered $(12-15,18,19)$. There were opinions that these correlations were mediated by the bone mass, and if BMD was controlled, these relationships would revert to become non-significant (18). However, a computer simulation study performed by HaÏat et al. showed that after adjusting for BMD, $\mathrm{BV} / \mathrm{TV}$ remained significantly associated with SOS (20). This was confirmed by later studies using excised samples, whereby microarchitecture of the bone was significantly associated with SOS and contributed to the variation of SOS apart from BMD $(12,15)$. Bone biomechanical studies revealed that Young's modulus, compressive modulus, ultimate strength and elasticity of bone were significantly associated with $\operatorname{SOS}(12,16,21)$. Cavani et al. indicated that the combination of bone density and Young's modulus could explain $93.34 \%$ of the in vitro variation of SOS (12). Studies also showed that BUA was significantly associated with biomechanical parameters (21), but Toyras et al. indicated that this was only true in low-density bone samples $(16,17)$. In high-density bovine samples, BUA failed to predict BMD and biomechanical strength $(16,17)$. These in vitro experiments (summarized in Table 1) showed that QUS indices are able to reflect the two principal constituents of bone health, which are the bone quantity (BMD and bone mass) and the bone quality (bone microarchitecture and strength). The stronger association between QUS indices and BMD indicates that bone quantity contributes to most of the variation in QUS (22).

In humans, there were significant correlations between QUS indices and BMD values at various body sites assessed cross-sectionally. Dane et al. reported that all three QUS indices, BUA, SOS and SI were significantly correlated to BMD at lumbar spine and femur in postmenopausal women, but only SOS correlated significantly to BMD at lumbar spine and femur in premenopausal women (23). In a study by Mészáros et al. in men, BUA correlated significantly and moderately with BMD at lumbar spine, femoral neck and radius midshaft. However, SOS did not correlate with the BMD at the aforementioned sites (6). In a longitudinal study by Trimpau et al. involving 80 Swedish women aged 53-73 years, BUA and SOS were significantly correlated with BMD at multiple skeletal sites at the first screening and the after seven years later. Furthermore, the changes of DXA and QUS measurements during the follow-up period were also significantly correlated (24). The ability of QUS to predict fractures were also validated in several human cohort studies. Hernandez et al. examined 5195 Spanish postmenopausal women $\geq 65$ years and found that all QUS indices (BUA, SOS, eBMD and QUI) were significantly different between subjects with and without history of fractures. Logistic regres- 
sion analysis also confirmed that these QUS indices were significantly associated with previous fractures (25). Similar findings were also found in men. The study of Varenna et al. in 4832 Italian men aged 60-80 years found that QUS indices (BUA, SOS, SI) were significant associated with history of hip fracture and non-spinal fracture (26). These observations from cross-sectional studies were further validated by prospective studies. In the Norfolk Cohort Study involving 14824 men and women aged 42-82 years followed for 1.9 years, Khaw et al. discovered that one
SD decrease in ultrasound velocity translated to a $60 \%$ increase in fracture risk in both genders. They also found that the risk increased for older subjects and doubled for subjects with history of fractures (27). In the Asian population, Fujiwara et al. showed that SOS, BUA and SI significantly predicted hip, wrist and non-spinal fractures in Japanese men and women followed for 5 years (28). In a recent meta-analysis, Moayyeri et al. concluded that SOS, BUA, SI and QUI significantly predicted fractures after reviewing 21 independent studies (29) (Table 2).

Table I. In vitro studies on the relationship between QUS and bone properties.

\begin{tabular}{|c|c|c|}
\hline Researchers (year) & Sample & Findings \\
\hline $\begin{array}{l}\text { Bouxsein and } \\
\text { Radoff (1997) (21) }\end{array}$ & $\begin{array}{l}\text { Human cadaveric } \\
\text { calcaneal bone }\end{array}$ & $\begin{array}{l}\text { BUA and SOS of intact heel correlated significantly with compressive modulus and ultimate } \\
\text { strength, but the correlations were inferior compared to BMD and apparent density. Com- } \\
\text { bining BUA and BMD or apparent density increased the association with elastic modulus. } \\
\text { Combining BUA and SOS explained 7-12\% of the variance in trabecular bone mechanical } \\
\text { properties. }\end{array}$ \\
\hline $\begin{array}{l}\text { Hans et al. } \\
\text { (1999) (14) }\end{array}$ & $\begin{array}{l}\text { Human cadaveric spinal } \\
\text { bone }\end{array}$ & $\begin{array}{l}\text { SOS was measured from sagittal, coronal and axial axes. SOS correlated significantly with } \\
\text { BMD, BV/TV, Tb.Sp., Tb.N., fractal dimension and elasticity. After adjusting for BMD, the } \\
\text { correlation between SOS and elasticity at coronal axis remained significant. Using multivari- } \\
\text { ate regression, most of the variation in SOS was contributed by BMD and the contributions of } \\
\text { elasticity and anisotropy were small. }\end{array}$ \\
\hline $\begin{array}{l}\text { Trebacz and Natali } \\
\text { (1999) (19) }\end{array}$ & $\begin{array}{l}\text { Human cadaveric } \\
\text { calcaneal and L1 } \\
\text { vertebral bone. }\end{array}$ & $\begin{array}{l}\text { The relationships between SOS with bone ash density, BV/TV and Tb.Th. were significant. } \\
\text { The combination of the aforementioned factors contributed to } 83 \% \text { of the variation in SOS. } \\
\text { BV/TV was a significant predictor for BUA. }\end{array}$ \\
\hline $\begin{array}{l}\text { Toyras et al. } \\
(1999)(16)\end{array}$ & $\begin{array}{l}\text { Trabecular sample from } \\
\text { bovine femur and tibia. }\end{array}$ & $\begin{array}{l}\text { SOS was associated with BMD, Young's modulus or ultimate strength in bovine trabecular } \\
\text { sample but BUA was not. In vivo study showed that BUA was associated with BMD in human } \\
\text { calcaneus. BUA was not suitable in measurement for high density sample. }\end{array}$ \\
\hline $\begin{array}{l}\text { Toyras et al. } \\
(2002)(17)\end{array}$ & $\begin{array}{l}\text { Trabecular sample from } \\
\text { bovine femur and tibia. }\end{array}$ & $\begin{array}{l}\text { BUA correlated negatively with vBMD and storage modulus. SOS correlated positively and } \\
\text { strongly with vBMD and storage modulus but negatively with tangent loss. BUA could not } \\
\text { predict mechanical properties of the bone with high density. }\end{array}$ \\
\hline $\begin{array}{l}\text { Cortet et al. } \\
\text { (2003) (13) }\end{array}$ & $\begin{array}{l}\text { Human cadaveric } \\
\text { calcaneal bone. }\end{array}$ & $\begin{array}{l}\text { SOS was correlated significantly with BMD, BV/TV, Tb.Th., Tb.Sp., and Tb.N. The combina- } \\
\text { tion of the factors such as trabecular pattern and fractal dimension contributed to } 17.8 \% \text { var- } \\
\text { iation in SOS other than BMD. }\end{array}$ \\
\hline $\begin{array}{l}\text { Chaffai et al. } \\
\text { (2002) (18) }\end{array}$ & $\begin{array}{l}\text { Human cadaveric } \\
\text { calcaneal bone. }\end{array}$ & $\begin{array}{l}\text { All QUS indices (nBUA, UVB and BUB) correlated significantly with BMD and microarchi- } \\
\text { tecture parameters of bone (BV/TV, BS/BV, Tb.Th., Tb.N., Tb.Sp., N.Nd) but all these corre- } \\
\text { lations were independent of BMD. In stepwise regression model, BMD was significant pre- } \\
\text { dictor for UVB. }\end{array}$ \\
\hline $\begin{array}{l}\text { HaÏat et al. } \\
\text { (2007) (20) }\end{array}$ & $\begin{array}{l}\text { Computer simulation of } \\
\text { trabecular sample from } \\
\text { human cadaveric femur. }\end{array}$ & $\begin{array}{l}\text { The variation in BV/TV exerted most significant influence on BUA and SOS compared to } \\
\text { other factors such as density, stiffness and microarchitecture of the bone. After adjustment for } \\
\text { BMD, most variations in SOS and BUA were determined by BV/TV. }\end{array}$ \\
\hline $\begin{array}{l}\text { Cavani et al. } \\
(2008)(12)\end{array}$ & $\begin{array}{l}\text { Cylindrical bone sample } \\
\text { from equine vertebrae. }\end{array}$ & $\begin{array}{l}\text { SOS correlated with volumetric BMD, BV/TV, BS/TV, Tb.N., Tb.Th., Tb.Sp. and Young's } \\
\text { Modulus. After adjustment for vBMD, SOS was significantly correlated with BV/TV, BS/TV } \\
\text { and Young's modulus. A total of } 93.34 \% \text { of the variation in SOS was contributed by BMD and } \\
\text { Young's modulus. }\end{array}$ \\
\hline $\begin{array}{l}\text { Padilla et al. } \\
(2008)(15)\end{array}$ & $\begin{array}{l}\text { Human cadaveric } \\
\text { femoral bone. }\end{array}$ & $\begin{array}{l}\text { All QUS parameters (SOS, BUB and nBUA) were correlated with BMD. SOS was correlated } \\
\text { significantly with microarchitecture parameters of the bone (Tb.Th., BS/BV, Tb.N., Tb.Sp., } \\
\text { Euler, incidence angle, RV/BV and BV/TV). In multiple regression analysis, microarchitec- } \\
\text { tural parameters contributed } 19 \% \text { of the variation in SOS apart from BMD. }\end{array}$ \\
\hline
\end{tabular}

Abbreviation: $\mathrm{BMD}=$ bone mineral density; $\mathrm{BS} / \mathrm{BV}=$ specific bone surface; $\mathrm{BUA}=$ broadband attenuation of sound; $\mathrm{BUB}=\mathrm{broadband}$ ultrasound backscatter; $\mathrm{BV} / \mathrm{TV}=\mathrm{bone}$ volume; $\mathrm{nBUA}=$ normalized broadband ultrasound attenuation; $\mathrm{N} . \mathrm{Nd}$.=node number; $\mathrm{RV} / \mathrm{BV}=$ node ratios over bone volume; $\mathrm{QUS}=\mathrm{quantitative}$ ultrasound; $\mathrm{SD}=\mathrm{standard}$ deviation; $\mathrm{SOS}=$ speed of sound; Tb.N.=trabecular number; Tb.Sp.=trabecular separation; Tb.Th. =trabecular thickness; UVB=ultrasound velocity though bone. 
Table 2. In vivo studies on the relationship between QUS and bone properties.

\begin{tabular}{ll} 
Researcher (year) & Subject and Study Type \\
\hline $\begin{array}{l}\text { Hernandez et al. } \\
\text { (2004) (25) }\end{array}$ & $\begin{array}{l}5195 \text { Spanish women aged } 65 \text { years } \\
\text { older. Cross-sectional study. }\end{array}$ \\
$\begin{array}{l}\text { Gonnelli et al. } \\
\text { (2005) (30) }\end{array}$ & Cross-sectional study.
\end{tabular}

(2005) (30) Cross-sectional study.

Varenna et al.

(2005) (26)

Khaw et al.

(2004) (27)

Fujiwara et al. (2005) (28)

Damilaski et al. (2007) (49)

Meszaros et al. (2007) (6)

4832 Italian men aged $60-80$ years. Cross-sectional study.

The Norfolk cohort of the European Prospective Investigation into Cancer. 14824 men and women analysed together (42-82 years). Prospective study: follow-up for an average of 1.9 years. 1004 Japanese men and 3024 Japanese women. Prospective study: follow-up for an average of 5 years.

30 postmenopausal women with hip fractures and 30 healthy women. Cross-sectional study.

\section{7 men, 27-78 years. Cross-sectional} study.

Bauer et al.(2007) 5607 US men aged $\geq 65$ years. Prospec(50) tive study: follow-up for an average of 4.2 years.

Dane et al. (2008) 351 pre- and postmenopausal women. (23) Cross-sectional study.

El Maghraoui et 295 postmenopausal women aged al. (2009) (33) 60 - 84. Cross-sectional study.

Kwok et al. (2012) (32)

1921 Hong Kong Chinese men aged 65-92 years. Prospective study: follow-up for an average of 6.5 years.

Chan et al. (2012) 454 women and 445 men aged 62-89 (31) years. Prospective study: 13 years.

Findings

All QUS parameters (eBMD, BUA, SOS, QUI) were significantly different between Spanish women with and without history of osteoporotic fractures. QUS parameters showed significant association with previous fractures.

All QUS and DXA parameters were significantly different between men with and without fractures. QUS at heel had better discriminatory ability compared to QUS at fingers. As shown by receiver operating characteristics curve, SOS had discriminatory ability same as femoral neck BMD. The association between SOS and previous fractures was significant and higher than BUA but lower than stiffness.

Hip and non-spinal fractures were significantly associated with SOS, BUA and SI.

1 SD decrease in VOS caused a $60 \%$ increase in fracture risk (both gender), higher risk for older subjects, and doubled for subjects with previous fractures.

SOS, BUA and SI significantly predicted fractures. SOS and SI were better predictors than BUA. The short term prediction (5 years) was better than long term prediction $(>5-10$ years).

ROC curve showed that BUA, SOS and SI were able to differentiate hip-fractured and non-hip-fracture in postmenopausal women. BUA and SI showed significant discriminability at hip fracture but were not superior to BMD at the hip.

BUA and SOS were significantly correlated with BMD. SOS was better at discriminating between subject with and without fractures. Discriminatory ability of SOS to vertebral fractures was the best as assessed using AUC compared to BMD and BUA.

BUA significantly predicted hip fracture and any non-spine fracture. Combining BUA and BMD was not superior to each indicator alone in the prediction. Other QUS indices were the same.

BUA, SOS and SI significantly correlated with BMD at lumbar spine and femur in postmenopausal women. Only SOS significantly correlated with BMD spine and femur in pre-menopausal women. AUC showed that the QUS showed poor performance in discriminating osteoporotic and normal subjects.

BUA correlated weakly and significantly with BMD at the hip, lumbar spine and femur. Only lumbar spine BMD significantly predicted vertebral fracture in asymptomatic women, but QUS did not. Combination of QUS and BMD did not improve the predictability.

BUA and QUI were significantly associated with non-vertebral fractures and major fragility fractures, but the prediction of hip and spine BMD were better in major fragility fractures. Combining hip BMD and QUS indices did not improve the prediction.

In women, the combination of BUA and femoral neck BMD predicted fragility fractures (hip, vertebral or any fractures) better than BMD alone. In men, the combination did not improve the prediction.

Abbreviation: $\mathrm{AUC}=$ area under the curve; $\mathrm{BMD}=$ bone mineral density; $\mathrm{BUA}=$ broadband attenuation of sound; $\mathrm{eBMD}=\mathrm{estimated}$ bone mineral density; $\mathrm{QUI}=\mathrm{quantitative}$ ultrasound index; $\mathrm{QUS}=$ quantitative ultrasound; $\mathrm{SD}=$ standard deviation; $\mathrm{SI}=$ stiffness index; $\mathrm{SOS}=$ speed of sound.

\section{The Comparison of Fracture Prediction between QUS and DXA}

Several studies showed that the fracture prediction by QUS was equal and sometimes better than DXA. In cross-sectional studies by Mészáros et al. (6) and Gonnelli et al.(30) involving male subjects, both SOS and BUA were able to discriminate subjects with fractures from those without. Both studies also revealed that SOS had better or the same discriminatory ability than $\operatorname{BMD}(6,30)$. In a longitudinal study by Chan et al., the combination of BUA and femoral neck BMD predicted hip, vertebral or any fractures better than individual indices in postmenopausal women but not in men followed for 13 years (31). On the other hand, some studies reported that BMD had better discriminability than QUS, and the combination of DXA and QUS did not improve predictability. A study by Kwok et al. in 1921 Hong Kong Chinese men followed for 6.5 years demonstrated that BUA, QUI and BMD (hip and spine) significantly predicted major fragility fractures and non-vertebral fractures, but BMD was better in predicting the former. In addition, the combination of BMD and QUS did not improve fracture predictability (32). El Maghraoui et al. reported that only lumbar spine BMD predicted verte- 
bral fractures in postmenopausal women but QUS did not (33). Dane et al. showed similar results in pre- and postmenopausal women in their study (23). In view of the heterogeneity of the results on the comparison, a meta-analysis was performed by Marín et al. It was revealed that the predictability of QUS in non-spinal fractures was similar to DXA, but DXA was more superior in predicting hip fractures (34) (Table 2).

\section{Controversy in QUS Bone Assessment}

According to the official position of ISCD on QUS bone assessment, several aspects concerning the use of T-score, reference range, precision and inter-device comparison were addressed (10). In the classification of low bone density using DXA, T-score with cut-off points of $\leq-1.0$ SD for osteopenia and $\leq-2.5$ SD for osteoporosis are used (2). However, the use of the same cut-off points in QUS measurement is not recommended because QUS and DXA essentially employ different technology in assessing bone health (10). Several studies also showed that simply applying the conventional DXA cut-offs in QUS measurement significantly underestimates the true prevalence of osteoporosis $(35,36)$. A number of cut-off points for bone health classifications for QUS had been suggested previously, but they were specific to the device used (37-39). As an example, Frost et al. reported that T-score cut off values for osteoporosis were -1.61, -1.94 and -1.90 for BUA, SOS and eBMD measured using Hologic Sahara ultrasonometer, and -1.45 and -2.10 for BUA and SOS measured using Osteometer DTUone (38). The use of an appropriate reference range is important for accurate classification of bone health using QUS and DXA. For example, a Caucasian reference range, where bone density outcomes are typically higher than Asian bone density outcomes, will eventuate in Asian subjects being classified as having low bone density. Chin et al. reported that even the use of references from different Asian countries caused significant discrepancies in the classification of subjects with low bone health (40). The normative values for different populations around the world had been generated for various QUS devices (36, 40-44). Both the population of interest and the device used should be considered when incorporating the respective normative values in QUS device. Due to the fact that numerous QUS devices have been developed by many manufactures, each with its own designed logarithm for the calculation and interpretation of QUS indices, inter-device comparison of the results of bone health assessment is not advised (10). The precision of QUS devices was reported to be poorer compared to DXA devices (45). This may be one of the reason QUS devices are not recommended for patient follow-up in the treatment of osteoporosis unless DXA is inaccessible (10). The precision values of SOS and BUA are different due to the effect of a large denominator of the former, hence SOS tends to have smaller precision values (45). An example for precision values reported for the CUBA McCue instrument were $2.4 \%$ for BUA and $0.3 \%$ for SOS (46).

We suggest that for the use of QUS in the screening of bone health in local community, an ultrasonometer validated against DXA should be used. The ultrasonometer should also be equipped with the local reference curve (or a reference curve from a population with the most similar background) for the purpose of bone health classification. Short-term and long-term in vivo precision of the device should be established for the purpose of the follow-up of subjects. The papers by Bonnick et al. (47) and Gluer et al. (48) should be referred for steps to establish the precision values. Furthermore, QUS results should be interpreted with clinical risk factors for maximal detection of subjects with osteoporosis.

\section{Summary}

Quantitative ultrasound technology emerges as a convenient tool for osteoporosis screening. It provides additional information on bone microarchitectures as well as BMD. Several studies also indicated that it can predict fractures for both genders. In developing countries with poor accessibility to DXA, QUS could be used as an effective screening tool for early detection of osteoporosis. An early detection would allow preventive measures to be taken to hinder the progression of the osteoporosis.

\section{Acknowledgment}

We thank Universiti Kebangsaan Malaysia for providing the research grant DIP-2012-07.

\section{Conflict of Interest}

The authors reported no conflict of interest.

\section{References}

1. Doran PM, Khosla S. Osteoporosis. In: Hall JE, Nieman LK, editors. Contemporary Endocrinology: Handbook of Diagnostic Endocrinology. Totowa, NJ.: Humana Press; 2003:: 257-75.

2. World Health Organization. Assessment of fracture risk and its application to screening for postmenopausal osteoporosis: report of a World Health Organization Study Group. WHO Technical Report Series No 843. Geneva: World Health Organization. 1994.

3. Handa R, Ali Kalla A, Maalouf G. Osteoporosis in developing countries. Best Pract Res Clin Rheumatol. 2008; 22: 693-708.

4. Laugier P. An overview of bone sonometry. Int Congr Ser. 2004; 1274: 23-32.

5. Miura S, Saavedra OL, Yamamoto S. Osteoporosis in urban post-menopausal women of the Philippines: prevalence and risk factors. Arch Osteoporos. 2008; 3: 17-24.

6. Meszaros S, Toth E, Ferencz V, Csupor E, Hosszu E, Horvath C. Calcaneous quantitative ultrasound measurements predicts vertebral fractures in idiopathic male osteoporosis. Joint Bone Spine. 2007; 74: 79-84.

7. Baroncelli GI. Quantitative Ultrasound Methods to Assess Bone Mineral Status in Children: Technical Characteristics, Performance, and Clinical Application. Pediatr Res. 2008; 63: 220-8. 
8. Mimura K, Yamamoto T, Nakatuka K, Yoh K, Arai T. Infant bone quantity measurement - Hoping for the growth of smooth bone. Clin Calcium. 2008; 18: 1014-27.

9. Guglielmi G, de Terlizzi F. Quantitative Ultrasound in the assessment of Osteoporosis. Eur J Radiol. 2009; 71: 425-31.

10. Krieg M-A, Barkmann R, Gonnelli S, Stewart A, Bauer DC, Barquero LDR, et al. Quantitative Ultrasound in the Management of Osteoporosis: The 2007 ISDN Official Positions. J Clin Densitom. 2008; 11: 163-87.

11. Wasnich R, Davis J, Ross P, Vogel J. Effect of thiazide on rates of bone mineral loss: a longitudinal study. BMJ. 1990; 301: 1303-5.

12. Cavani F, Giavaresi G, Fini M, Bertoni L, de Terlizzi F, Barkmann R, et al. Influence of density, elasticity, and structure on ultrasound transmission through trabecular bone cylinders. IEEE Trans Ultrason Ferroelectr Freq Control 2008; 55: 1465-72.

13. Cortet B, Boutry N, Dubois P, Legroux-Gérot I, Cotten A, Marchandise X. Does quantitative ultrasound of bone reflect more bone mineral density than bone microarchitecture? Calcif Tissue Int. 2004; 74: 60-7.

14. Hans D, Wu C, Njeh CF, Zhao S, Augat P, Newitt D, et al. Ultrasound Velocity of Trabecular Cubes Reflects Mainly Bone Density and Elasticity. Calcif Tissue Int. 1999; 64: 18-23.

15. Padilla F, Jenson F, Bousson V, Peyrin F, Laugier P. Relationships of trabecular bone structure with quantitative ultrasound parameters: In vitro study on human proximal femur using transmission and backscatter measurements. Bone. 2008; 42: 1193-202.

16. Töyräs J, Kröger H, Jurvelin JS. Bone properties as estimated by mineral density, ultrasound attenuation, and velocity. Bone. 1999; 25: 725-31.

17. Töyräs J, Nieminen MT, Kröger H, Jurvelin JS. Bone mineral density, ultrasound velocity, and broadband attenuation predict mechanical properties of trabecular bone differently. Bone. 2002; 31: 503-7.

18. Chaffaí S, Peyrin F, Nuzzo S, Porcher R, Berger G, Laugier P. Ultrasonic characterization of human cancellous bone using transmission and backscatter measurements: relationships to density and microstructure. Bone. 2002; 30: 229-37.

19. Trebacz H, Natali A. Ultrasound Velocity and Attenuation in Cancellous Bone Samples from Lumbar Vertebra and Calcaneus. Osteoporos Int. 1999; 9: 99-105.

20. Haïat G, Padilla F, Peyrin F, Laugier P. Variation of Ultrasonic Parameters With Microstructure and Material Properties of Trabecular Bone: A 3D Model Simulation. J Bone Miner Res. 2007; 22: 665-74.

21. Bouxsein ML, Radloff SE. Quantitative Ultrasound of the Calcaneus Reflects the Mechanical Properties of Calcaneal Trabecular Bone. J Bone Miner Res. 1997: 12 : 839-46.

22. Wear KA, Nagaraja S, Dreher ML, Gibson SL. Relationships of quantitative ultrasound parameters with cancellous bone microstructure in human calcaneus in vitro. J Acoust Soc Am. 2012; 131: 1605-12.

23. Dane C, Dane B, Cetin A, Erginbas M. The role of quantitative ultrasound in predicting osteoporosis defined by dual-energy X-ray absorptiometry in preand postmenopausal women. Climacteric. 2008; 11: 296-303.

24. Trimpou P, Bosaeus I, Bengtsson B- $\AA$, Landin-Wilhelmsen K. High correlation between quantitative ultrasound and DXA during 7 years of follow-up. Eur J Radiol. 2010; 73: 360-4.

25. Hernandez JL, Marin F, Gonzalez-Macias J, Diez-Perez A, Vila J, Gimenez S, et al. Discriminative capacity of calcaneal quantitative ultrasound and of osteoporosis and fracture risk factors in postmenopausal women with osteoporotic fractures. Calcif Tissue Int. 2004; 74: 357-65.

26. Varenna M, Sinigaglia L, Adami S, Giannini S, Isaia G, Maggi S, et al. Association of quantitative heel ultrasound with history of osteoporotic fractures in elderly men: the ESOPO study. Osteoporos Int. 2005; 16: 1749-54.

27. Khaw KT, Reeve J, Luben R, Bingham S, Welch A, Wareham N, et al. Prediction of total and hip fracture risk in men and women by quantitative ultrasound of the calcaneus: EPIC-Norfolk prospective population study. Lancet. 2004; 363: 197-202.

28. Fujiwara S, Sone T, Yamazaki K, Yoshimura N, Nakatsuka K, Masunari N, et al. Heel bone ultrasound predicts non-spine fracture in Japanese men and women. Osteoporos Int. 2005; 16: 2107-12.

29. Moayyeri A, Adams J, Adler R, Krieg MA, Hans D, Compston J, et al. Quantitative ultrasound of the heel and fracture risk assessment: an updated meta-analysis. Osteoporos Int. 2012; 23: 143-53.

30. Gonnelli S, Cepollaro C, Gennari L, Montagnani A, Caffarelli C, Merlotti D, et al. Quantitative ultrasound and dual-energy X-ray absorptiometry in the prediction of fragility fracture in men. Osteoporos Int. 2005; 16: 963-8.

31. Chan MY, Nguyen ND, Center JR, Eisman JA, Nguyen TV. Absolute fracture-risk prediction by a combination of calcaneal quantitative ultrasound and bone mineral density. Calcif Tissue Int. 2012; 90: 128-36.

32. Kwok T, Khoo CC, Leung J, Kwok A, Oin L, Woo J, et al. Predictive values of calcaneal quantitative ultrasound and dual energy $X$ ray absorptiometry for non-vertebral fracture in older men: results from the MrOS study (Hong Kong). Osteoporos Int. 2012; 23: 1001-6.

33. El Maghraoui A, Morjane F, Mounach A, Ghazi M, Nouijai A, Achemlal L, et al. Performance of calcaneus quantitative ultrasound and dual-energy X-ray absorptiometry in the discrimination of prevalent asymptomatic osteoporotic fractures in postmenopausal women. Rheumatol Int. 2009; 29: 551-6.

34. Marín F, González-Macías J, Díez-Pérez A, Palma S, Delgado-Rodríguez M. Relationship Between Bone Quantitative Ultrasound and Fractures: A Meta-Analysis. J Bone Miner Res. 2006; 21: 1126-35.
35. Rhee Y, Lee J, Jung JY, Lee JE, Park SY, Kim YM, et al. Modifications of T-Scores by Quantitative Ultrasonography for the Diagnosis of Osteoporosis in Koreans. J Korean Med Sci. 2009; 24: 232-6.

36. Kastelan D, Kujundzic-Tiljak M, Kraljevic I, Kardum I, Giljevic Z, Korsic M. Calcaneus ultrasound in males: Normative data in the Croatian population (ECUM study). J Endocrinol Invest. 2006; 29: 221-5.

37. Frost ML, Blake GM, Fogelman I. Contact Quantitative Ultrasound: An Evaluation of Precision, Fracture Discrimination, Age-Related Bone Loss and Applicability of the WHO Criteria. Osteoporos Int. 1999; 10: 441-9.

38. Frost ML, Blake GM, Fogelman I. Can the WHO Criteria for Diagnosing Osteoporosis be Applied to Calcaneal Quantitative Ultrasound? Osteoporos Int. 2000; 11: 321-30.

39. Kishimoto H, Yoh K, Ohta H, Gorai I, Hashimoto J, Nakatsuka K, et al. Normative data and Cut-Off values Determined Using Quantitative Ultrasound CM-100 in Japanese Women. Osteoporosis Japan 2003; 11: 129-32.

40. Chin KY, Soelaiman IN, Mohamed IN, Mohamed N, Shuid AN, Muhammad $\mathrm{N}$, et al. Discrepancy Between the Quantitative Ultrasound Value of Malaysian Men and the Manufacturer's Reference and the Impact on Classification of Bone Health Status. J Clin Densitom. 2013; 16: 189-95.

41. Zanovec M, Wang J, West Ii KM, Tuuri G. Quantitative Ultrasound Normative Reference Data for Community-Dwelling White and Black Females in the United States. J Clin Densitom. 2011; 14: 116-21.

42. Trovas G, Tsekoura M, Galanos A, Dionyssiotis Y, Dontas I, Lyritis G, et al. Quantitative Ultrasound of the Calcaneus in Greek Women: Normative Data are Different From the Manufacturer's Normal Range. J Clin Densitom. 2009; 12: 353-9.

43. Maggi S, Noale M, Gonnelli S, Nuti R, Di Munno O, de Feo D, et al. Quantitative Ultrasound Calcaneous Measurements: Normative Data for the Italian Population. The ESOPO Study. J Clin Densitom. 2007; 10: 340-6.

44. Zhu Z-Q, Liu W, Xu C-L, Han S-M, Zu S-Y, Zhu G-J. Reference data for quantitative ultrasound values of calcaneus in 2927 healthy Chinese men. J Bone Miner Metab. 2008; 26: 165-71.

45. Knapp KM. Quantitative ultrasound and bone health. Salud Pública de México. 2009; 51: s18-s24.

46. Zochling J, Nguyen TV, March LM, Sambrook PN. Quantitative ultrasound measurements of bone: measurement error, discordance, and their effects on longitudinal studies. Osteoporos Int. 2004; 15: 619-24.

47. Bonnick SL, Johnston Jr CC, Kleerekoper M, Lindsay R, Miller P, Sherwood L, et al. Importance of Precision in Bone Density Measurements. J Clin Densitom. 2001; 4 : 105-10.

48. Glüer CC, Blake G, Lu Y, Blunt BA, Jergas M, Genant HK. Accurate assessment of precision errors: How to measure the reproducibility of bone densitometry techniques. Osteoporos Int. 1995; 5: 262-70.

49. Damilakis J, Papadokostakis G, Perisinakis K, Maris TG, Karantanas AH. Hip fracture discrimination by the Achilles Insight QUS imaging device. Eur J Radiol. 2007; 63: 59-62.

50. Bauer DC, Ewing SK, Cauley JA, Ensrud KE, Cummings SR, Orwoll ES. Quantitative ultrasound predicts hip and non-spine fracture in men: the MrOS study. Osteoporos Int. 2007; 18: 771-7. 